\title{
Utilizing waste materials to enhance mechanical and durability characteristics of concrete incorporated with silica fume
}

\author{
Ali Hamza ${ }^{1}$, Shahram Derogar ${ }^{2}$, and Ceren Ince ${ }^{1}$ \\ ${ }^{1}$ Civil Engineering Department, Middle East Technical University, Northern Cyprus Campus, Kalkanl, \\ Güzelyurt, North Cyprus via Mersin 10, Turkey \\ ${ }^{2}$ Civil Engineering Department, European University of Lefke, Lefke, North Cyprus via Mersin 10, \\ Turkey
}

\begin{abstract}
Construction and demolition wastes are increasing significantly due to augmented boom of modern construction. Although the partial cement replacement materials do promote the idea of sustainable construction, the use of construction and demolition waste can also be considered to be viable option to advance the sustainability in modern construction practices. This paper investigates the use of industrial waste materials namely marble dust and crushed bricks as replacement of natural fine aggregates along with the use of silica fume as a partial cement replacement on the mechanical properties and durability characteristics of concrete. Partial replacement levels of waste materials were 10 and 20 percent by volume while the partial replacement level of silica fume was kept to 20 percent at all concrete samples. The results reported in this paper show that the use of marble dust as a replacement material to the natural fine aggregates resulted in an increase in the mechanical properties of concrete. However, the use of crushed bricks did not substantially contribute in the development of strength. Water permeability of concrete incorporated with both silica fume and waste materials (marble dust and crushed bricks) decreased significantly. The decrease in water permeability of concrete was attributed to the pozzolanic reaction of silica fume with calcium hydroxide of cement and the filler effect of the waste materials of marble dust and crushed bricks. The use of waste materials also enhance the freeze and thaw resistance of concrete. Authors strongly suggest that the pozzolanic reaction and the development of the microstructure of the concrete through the use of waste materials are largely responsible from the advances in the durability of concrete.
\end{abstract}

\section{Introduction}

Construction and Demolition Waste (CDW) is considered to be an alarming issue for our modern world. Significant portions of waste production are likely to be seen from

\footnotetext{
* Corresponding author: ali.hamza@metu.edu.tr
} 
manufacturing processes, industries and municipal waste [1]. With the increasing shortage of natural resources and ever increasing cost, waste utilization has become a great alternative for disposal [1]. Utilizing CDW seems practical; it promotes the development of sustainable construction practices [2]. In the literature, the use of supplementary cementitious materials (SCMs) especially silica fume contributes various improvements of mechanical properties and durability [3]. However, there is still a need to develop the sustainability in concrete manufacturing by reducing the burden on natural resources. Around $80 \%$ of volume of concrete is made of aggregates, which is normally derived from natural resources [2]. As the natural aggregates are continued to eventually receive their expiration date in various parts of the world, the concrete industry needs to seek for other possible alternatives [2].

Construction and demolition waste includes various types of wastes; rubbles, stones, recycled/crushed aggregates, industrial wastes such as marble dust, crushed bricks, saw dust etc. However, with respect to concrete, the common aspect among all of these waste materials is that they may contribute as a filler material in the concrete manufacturing [4]. Many research studies have highlighted the effects of filler materials on the properties of concrete manufacturing. Based on their conclusions, the benefit of filler material usage results in improved workability with reduced cement content $[5,6]$. Furthermore, due to their filler ability, pores between aggregates can be fulfilled improving the permeability and porosity of the concrete manufactured [7]. These waste materials can be pozzolanic or inert, depending on the physical and physio-chemical properties which may further affects the performance of concrete [8].

Marble, being commonly used building material contributes to a by-product environmental waste i.e. marble dust [9]. However, marble dust exhibits the properties of filler material due to its limestone origin [10], the possibility of use of marble dust as a filler material is likely to happen. According to $[10,11]$, use of limestone dust as a filler material showed quite good performance in concrete manufacturing. Brick and tile manufacturing industry produces quite a high number of rejected fired products due to being off-standard i.e. various bricks might be broken, underburned, overburned or distorted. Since bricks are porous and do possess the filler ability, they can be recycled in concrete as filler material [12, 13].

Therefore, the aim of this paper is to offer an integrative approach of using marble dust and crushed bricks as partial replacement of fine aggregates as filler material. Silica fume will also replace Portland cement up to $20 \%$ by volume. The idea is to investigate the possible role of marble dust and crushed bricks used as a partial replacement to fine aggregates along with incorporation of silica fume on the strength development and durability characteristics. Strength development includes compressive strength test as a key parameter being investigated. Tests such as water permeability and freezing/thawing resistance for determining the pore structure of concrete are included in the durability characteristics. The possible effect of addition of silica fume along with these filler replacement materials is also highlighted addressing its significant role on strength development and durability characteristics of the concrete.

\section{Materials and mix design}

This experimental study was directed on freshly-mixed and harden state concrete utilizing Portland cement and Silica Fume as binders. Type V Portland cement was attained from Adana Cimento Ltd. and conforms to [14]. Silica Fume was procured from Cyprus Environmental Enterprises Ltd. (CEE) and conforms to [15]. Waste materials being marble dust and crushed bricks will replace proportions of fine aggregates. Marble dust has been obtained from Izmer Ltd. whereas crushed bricks are obtained from Gurdag Madencilik Ltd. Apart from these materials, different components of concrete incorporates fine aggregates, 
coarse aggregates and water. Particle size distribution of marble dust and crushed bricks was necessary since these materials are to replace fine aggregates, the procedure is carried out conforming [16]. Various replacement levels of silica fume incorporated with marble dust and crushed bricks were used to investigate the significant role on the fresh and harden state properties of Portland cement concrete. Mix design calculations includes the assumption of slump value kept constant to $100 \mathrm{~mm}$. Hence, the water/binder $(\mathrm{w} / \mathrm{b})$ ratio have been maintained with respect to the slump value. The masses of binders and waste materials required to produce the mix proportions by volume were measured from precisely determined values of relative density. For fine and coarse aggregates, specific gravity was determined conforming $[17,18]$.

\section{Experimental procedures}

\subsection{Measurement of slump}

The slump of fresh concrete produced having different volume substitution levels of silica fume, marble dust and crushed bricks was measured utilizing the standard slump test apparatus [19]. The slump value has been kept consistent to $100 \mathrm{~mm}$. By keeping such consistency of slump value, the water/binder proportion has been kept between the limits of 0.50 to 0.70 .

\subsection{Measurement of compressive strength}

Compressive Strength testing was led on different harden substitution levels of concrete including silica fume, marble dust and crushed bricks collectively. The testing has been led from 28 days to 180 days on $150 \mathrm{~mm}$ standard blocks. Specimens from every substitution level were tested utilizing a compressive testing machine. The loading rate has been kept constant to $0.6 \mathrm{MPa} / \mathrm{sec}$. An average compressive strength has been taken among the substituted levels of concrete created as per [20].

\subsection{Measurement of water permeability}

Standard cubic molds of $150 \mathrm{~mm}$ were utilized for deciding the water permeability for every substitution level of concrete created. Every specimen was settled into the permeability testing machine and water has been infiltrated by capillary action from the base of the specimen. Adjustment of the specimen is critical on the permeability machine to eliminate the risk of water spillage from the sides of the specimen. All specimens were subjected to 1 atmospheric pressure $(0.1 \mathrm{MPa})$. It is significant to address that the mass measurements are needed to be taken before and after the test to ensure each specimen's water penetration limit. By following 72 hours, the test is completed. Every specimen was released from the permeability machine and split into two equivalent parts for deciding the water infiltration/penetration depth. Average depth was taken from four equidistant spots along the base of the specimen from where the water pressure has been applied. The system followed has been directed as per [21].

\subsection{Measurement of freeze and thaw resistance}

For freeze and thaw cycles, cubic molds of $150 \mathrm{~mm}$ have been set up in freeze and thaw cabinet. Similar methodology has been applied as reported by [22]. It incorporates freezing and thawing for the cured specimens of different substitution levels at $-30 \mathrm{oC}$ to $30 \mathrm{oC}$. Two 
cycles have been kept up once a day. For $12 \mathrm{~h}$ every day, the specimens have been encountering freezing and thawing consequently when the temperature comes to $-30 \mathrm{oC}$ or $30 \mathrm{oC}$. The cycle continues going twice every day for next 180 days. The relative humidity is kept up within the limits from $85 \%$ to $95 \%$. It is significant to mention that the surface of the specimens have not been secured during the freezing and thawing, so that the specimen is completely exposed to moisture variations.

\section{Experimental results}

\subsection{Effect of waste materials on the water content of concrete}

The effect of waste materials on the water content of concrete is investigated in this section. Crushed bricks and marble dust are used as sand replacement materials whereas silica fume is used as a cement replacement material for concrete. Figure 1 shows the slump (mm) versus the mix proportions of concrete. Water: binder is also shown in Figure 1 .

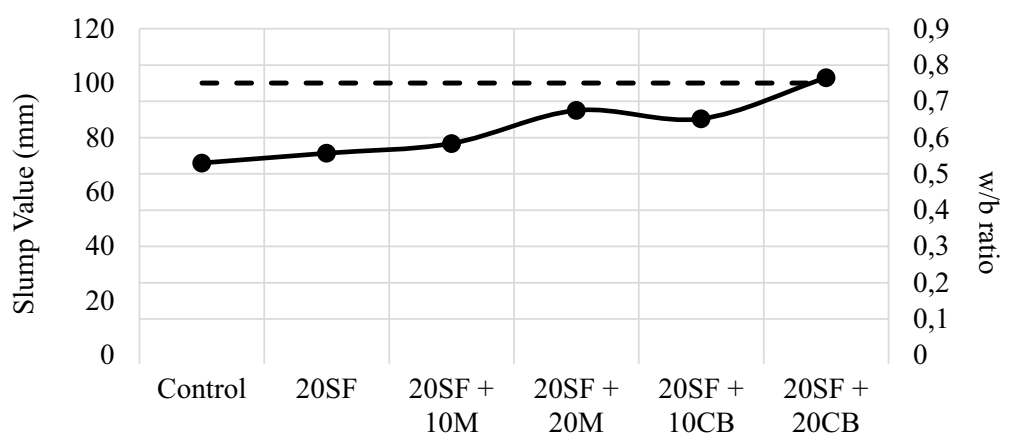

Mix Proportion

Fig. 1. Slump (mm) and water: binder ratios for all the mix proportions of concrete; slump values ( $\mathrm{mm}$ ), -----; water: binder ratio; SF: Silica Fume; CB: Crushed Brick and M: Marble Dust.

It is shown in Figure 1 that the use of silica fume as a cement replacement material resulted in an increase water: binder ratio to achieve the same consistency of control specimen. It is also shown in Figure 1 that the increase in the sand replacement materials such as marble dust and crushed bricks resulted in an increase in water: binder ratio to attain $100 \mathrm{~mm}$ of slump value. The increase in the water demand of concrete with increased replacement level of marble dust and crushed bricks are attributed to the finer particle size of the waste materials compared to sand. Finer particle size of waste materials used as a replacement to sand resulted in an increase water demand to attain constant slump value of $100 \mathrm{~mm}$.

\subsection{Effect of waste materials on the compressive strength of concrete}

Marble dust and crushed bricks are used as sand replacement materials and their replacement levels were 10 and $20 \%$. Silica fume is used as a cement replacement material and replacement level was kept constant to $20 \%$. Figure 2 shows the effect of the use of marble dust on the compressive strength of concrete incorporated with silica fume. The results show that the increase in the replacement level of marble dust resulted 
in a slight decrease in compressive strength of concrete compared to concrete that incorporated with only silica fume. It must however be noted that each replacement level of marble dust produced higher compressive strength both at 28, 90 and 180 days compared to the concrete control sample.

Influence of the use of crushed bricks on the compressive strength of concrete incorporated with silica fume is shown in Figure 3. It is shown in Figure 3 that the increase replacement level of crushed bricks resulted in a greater decrease in compressive strength of concrete compared to the compressive strength of concrete with replacement levels of marble dust. Although concrete with $10 \%$ replacement level of crushed bricks provide higher compressive strength than the concrete control specimen, compressive strength of concrete with $20 \%$ replacement level of crushed bricks fall below the compressive strength of control specimen.

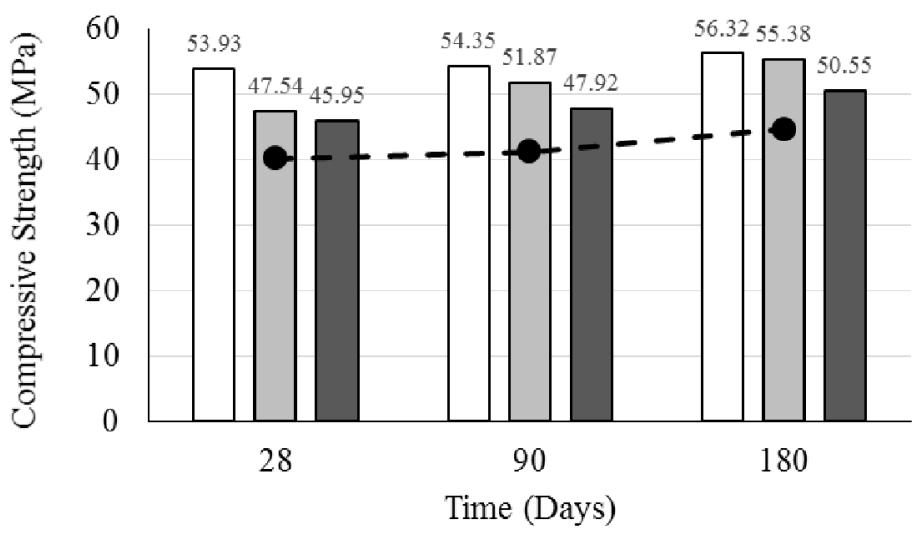

Fig. 2. Compressive strength of concrete incorporated with silica fume; $\% 20 \mathrm{SF} ; 20 \% \mathrm{SF}$ with $10 \%$ marble dust; $20 \%$ SF with $20 \%$ marble dust; concrete control specimen.

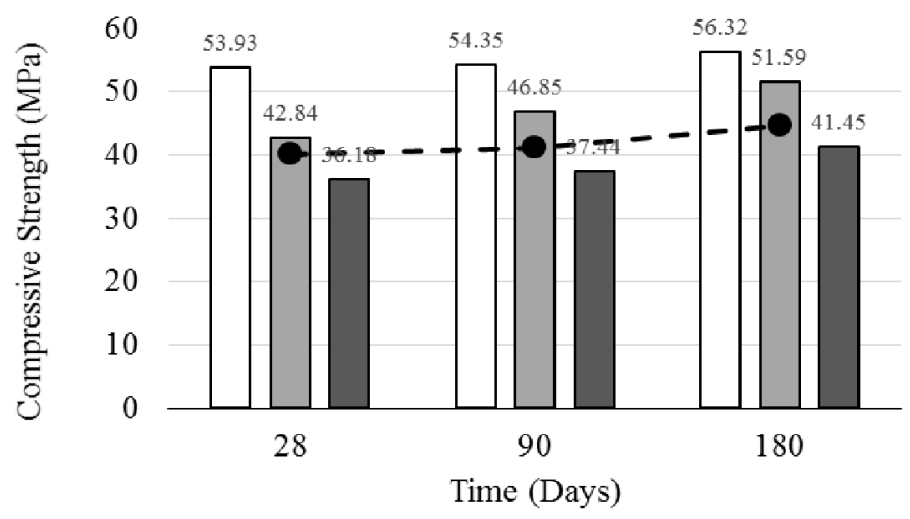

Fig. 3.

Compressive strength of concrete incorporated with silica fume; $\% 20$ SF; $20 \%$ SF with $10 \%$ crushed bricks; $20 \%$ SF with $20 \%$ crushed bricks; concrete control specimen. 


\subsection{The effect of waste materials on the water permeability of concrete}

The influence of the use of marble dust and crushed bricks as sand replacement material on the water permeability of concrete is studied in this section. Figure 4 show the water penetration depths of concrete specimens prepared using $20 \%$ silica fume and $20 \%$ silica fume with $20 \%$ marble dust and $20 \%$ crushed bricks.

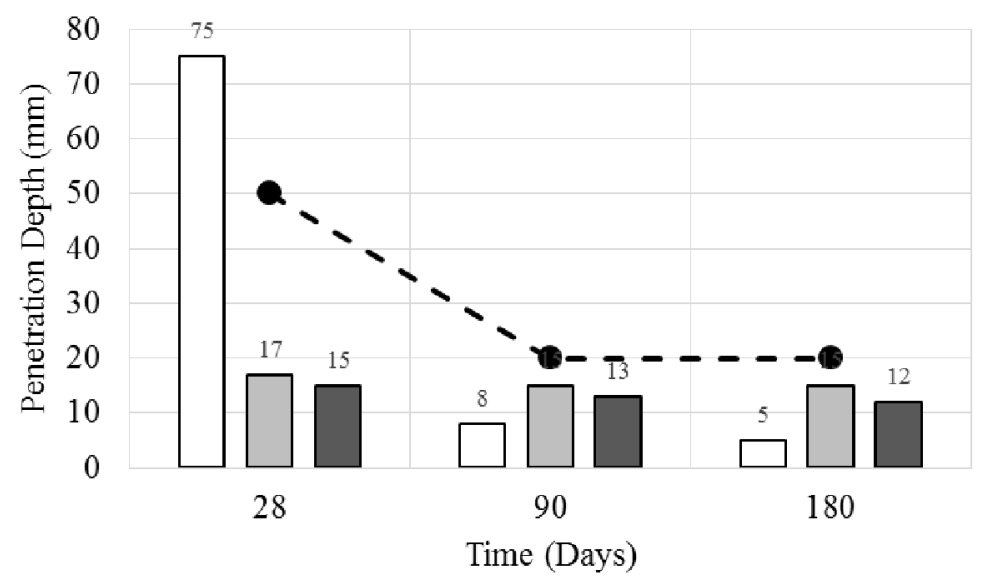

Fig. 4. Water penetration depth of concrete; $\% 20$ SF; $20 \%$ SF with $20 \%$ marble dust; $20 \%$ SF with $20 \%$ crushed bricks; concrete control specimen.

It is shown in Figure 4 that the use of $20 \%$ silica fume resulted in a great reduction in water penetration depth of concrete at 90 and 180 days. It must also be noted that the use of both $20 \%$ marble dust and $20 \%$ crushed bricks resulted in a dramatic decrease in the water penetration depth of concrete at $28^{\text {th }}$ days however, the water penetration of these samples remained constant at 90 and 180 days. It must be underlined here that both replacement materials resulted in a reduced water penetration of concrete at all test days and therefore enhanced the water permeability of concrete incorporated with silica fume.

\subsection{The effect of waste materials on the resistance to freeze and thaw of concrete}

The influence of the use of marble dust and crushed bricks as sand replacement material on the freeze and thaw resistance of concrete is studied in this section. Figure 5 shows the compressive strength of silica fume concrete prepared using 10 and $20 \%$ replacement level of marble dust that were subjected to freeze and thaw cycles for 28, 90 and 180 days. 


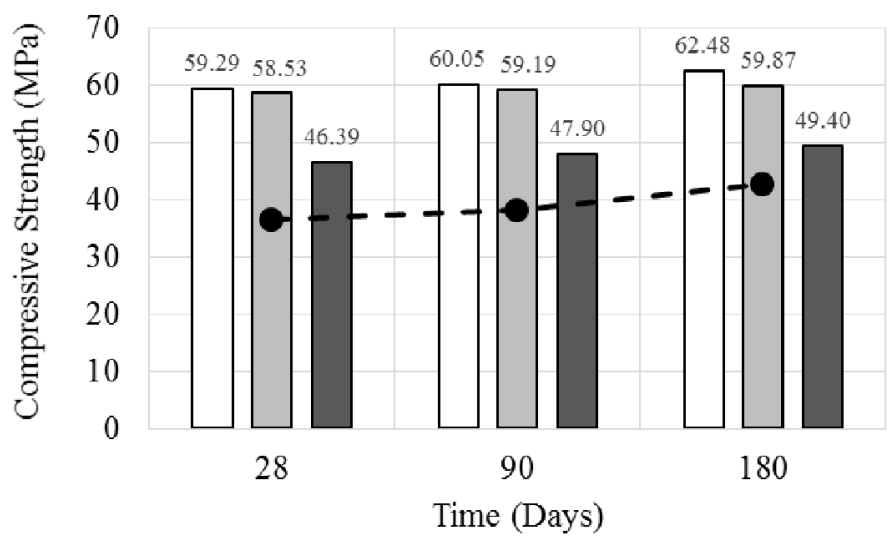

Fig. 5. Compressive strength of concrete subjected to freeze and thaw cycles; $\% 20$ SF; $20 \%$ SF with $10 \%$ marble dust; $20 \% \mathrm{SF}$ with $20 \%$ marble dust; concrete control specimen.

The results shown in Figure 5 indicate that the increase replacement levels of marble dust resulted in a decrease in freeze and thaw resistance compared to the concrete incorporated with silica fume only. It must however be underlined that the compressive strength concrete at all replacement levels of marble dust produced higher compressive strength compared to the control specimen at all test days. The results show that the use of marble dust in combination with a pozzolanic replacement material of silica fume enhances the freeze and thaw resistance compared to the control specimen.

Furthermore, Figure 6 shows the compressive strength of silica fume concrete prepared using 10 and $20 \%$ replacement level of crushed bricks that were subjected to freeze and thaw cycles for 28, 90 and 180 days.

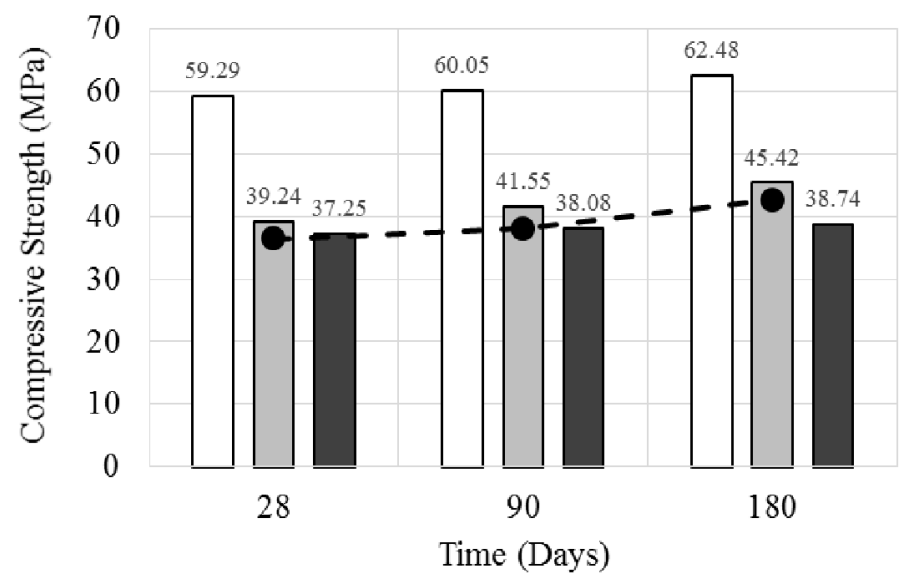

Fig. 6. Compressive strength of concrete subjected to freeze and thaw cycles; $\% 20$ SF; $20 \%$ SF with $10 \%$ crushed bricks; $20 \%$ SF with $20 \%$ crushed bricks; concrete control specimen.

It is shown in Figure 6 that the use crushed bricks as a replacement material to sand resulted in a great decrease in the compressive strength compared to compressive strength of concrete incorporated with silica fume only. While the compressive strength of concrete with $10 \%$ crushed bricks were almost equivalent to the compressive strength of control specimen, compressive strength of concrete with $20 \%$ replacement level of 
crushed bricks were less than that of the control. The results suggest that the use of crushed bricks are less effective in enhancing the freeze and thaw resistance of concrete than the marble dust. In both cases $10 \%$ replacement level provided a better resistance to freeze and thaw cycles of concrete.

\section{Conclusion}

The paper investigates the use of waste materials namely marble dust and crushed bricks on the strength development and durability of concrete. Marble dust and crushed bricks are used as sand replacement materials and $20 \%$ silica fume is also used as a cement replacement material for the preparation of concrete specimens. Replacement levels of the waste materials were 10 and $20 \%$. The results indicated that the increase in the waste replacement materials resulted in an increase water: binder ratio to attain the constant slump for concrete. The finer particle size of the waste materials were attributed for the increase in water content in order to attain the consistency of concrete samples constant. It must be noted that the use of both marble dust and crushed bricks enhanced the compressive strength compared to the control concrete. It must also be underlined that compressive strength of concrete incorporated with silica fume is decreased with the increase replacement levels of waste materials. Although the use of waste materials decreased the water penetration depth compared to the control specimen, the better resistance to water permeability is attain in concrete samples that were incorporated with silica fume. The results indicate the use of marble dust enhanced the freeze and thaw resistance compared to the control concrete however, no significant improvement is achieved with the replacement materials of crushed bricks. It must also be noted that the incorporation of silica fume alone, resulted in a greater resistance to freeze and thaw resistance of concrete. Therefore, these waste materials such as marble dust and crushed bricks do provide positive impact by reducing the burden of construction and demolition waste as they can be utilized in concrete manufacturing. Furthermore, the significance of improved mechanical properties and durability characteristics by using these waste materials along with silica fume contributes towards the field of sustainable construction.

Authors would like to thank Mr. Arsen Anc1, Director of Izmer Enterprises Ltd. and Mr. Necat from Gürdağ Madencilik Ltd. for material supply of marble dust and crushed bricks necessary for the experimental work of this study.

\section{References}

1. Vaidya, D., Performance of Marble Waste as Partially Replacement of Sand and Aggregate in Concrete. Imperial Journal of Interdisciplinary Research, 2(7) (2016)

2. Bektas, F., Wang, K. and Ceylan, H., Effects of crushed clay brick aggregate on mortar durability. Construction and Building Materials, 23(5), 1909-1914 (2009)

3. Behnood, A. and Ziari, H., Effects of silica fume addition and water to cement ratio on the properties of high-strength concrete after exposure to high temperatures. Cement and Concrete Composites, 30(2), 106-112 (2008)

4. Topcu, I.B., Bilir, T. and Uygunoğlu, T., Effect of waste marble dust content as filler on properties of self-compacting concrete. Construction and Building Materials, 23(5), 1947-1953 (2009)

5. Ye, G., Liu, X., De Schutter, G., Poppe, A.M. and Taerwe, L., Influence of limestone powder used as filler in SCC on hydration and microstructure of cement pastes. Cement and Concrete Composites, 29(2), 94-102 (2007) 
6. Poppe, A.M. and De Schutter, G., Cement hydration in the presence of high filler contents. Cement and Concrete Research, 35(12), 2290-2299 (2005)

7. Assie, S., Escadeillas, G. and Waller, V., Estimates of self-compacting concrete 'potential'durability. Construction and Building Materials, 21(10), 1909-1917 (2007)

8. Domone, P.L., Self-compacting concrete: An analysis of 11 years of case studies. Cement and Concrete Composites, 28(2), 197-208 (2006)

9. Corinaldesi, V., Moriconi, G. and Naik, T.R., Characterization of marble powder for its use in mortar and concrete. Construction and Building Materials, 24(1), 113-117 (2010)

10. Bonavetti, V., Donza, H., Menendez, G., Cabrera, O. and Irassar, E.F., Limestone filler cement in low w/c concrete: a rational use of energy. Cement and Concrete Research, 33(6), 865-871 (2003)

11. Yahia, A., Tanimura, M. and Shimoyama, Y., Rheological properties of highly flowable mortar containing limestone filler-effect of powder content and $\mathrm{W} / \mathrm{C}$ ratio. Cement and concrete Research, 35(3), 532-539 (2005)

12. Mansur, M.A., Wee, T.H. and Lee, S.C., Crushed bricks as coarse aggregate for concrete. Materials Journal, 96(4), 478-484 (1999)

13. Cavalline, T.L. and Weggel, D.C., 2013. Recycled brick masonry aggregate concrete: Use of brick masonry from construction and demolition waste as recycled aggregate in concrete. Structural Survey, 31(3), 160-180 (2013)

14. ASTM C150/C150M-16e1 Standard Specification for Portland Cement, ASTM International, West Conshohocken, PA (2016)

15. ASTM C1240-15 Standard Specification for Silica Fume Used in Cementitious Mixtures, ASTM International, West Conshohocken, PA (2015)

16. ASTM C33/C33M-16e1 Standard Specification for Concrete Aggregates, ASTM International, West Conshohocken, PA (2016)

17. ASTM C127-15 Standard Test Method for Relative Density (Specific Gravity) and Absorption of Coarse Aggregate, ASTM International, West Conshohocken, PA (2015)

18. ASTM C128-15 Standard Test Method for Relative Density (Specific Gravity) and Absorption of Fine Aggregate, ASTM International, West Conshohocken, PA (2015)

19. ASTM C143/C143M-15a Standard Test Method for Slump of Hydraulic-Cement Concrete, ASTM International, West Conshohocken, PA (2015)

20. BS EN 12390-3. Testing hardened concrete. Compressive strength of test specimens. London: BSI (2002)

21. BS EN 12390-8. Testing hardened concrete. Depth of penetration of water under pressure. London: BSI (2009)

22. Khoury, N.N. and Zaman, M.M., Environmental effects on durability of aggregates stabilized with cementitious materials. Journal of Materials in civil Engineering, 19(1), 41-48 (2007) 